\title{
Non-invasive proteomics - thinking about personalized breast cancer screening and treatment
}

\author{
Manuel Debald • Matthias Wolfgarten • \\ Gisela Walgenbach-Brünagel • Walther Kuhn • \\ Michael Braun
}

Received: 6 May 2010 / Accepted: 23 June 2010 /Published online: 14 July 2010

(C) European Association for Predictive, Preventive and Personalised Medicine 2010

\begin{abstract}
The early diagnosis of breast cancer in potentially curable stages improves prognosis and consecutively reduces mortality of breast cancer patients. Established screening programs have an unfavorable connotation due to significant rates of false negative as well as false positive results leading to overdiagnosis and overtherapy. The combination of a non-invasive breast-cancer-suspectability-biomarker with established clinical diagnostics could help to increase the acceptance of population based breast cancer screening programs by creating an individual risk profile, which is irrespective of mammography quality and interpretation. Recently, non-invasive proteomic biomarkers obtained from blood, saliva or nipple aspiration fluid have been extensively investigated and might play a future role in the personalized management of breast cancer screening. A simple, robust and inexpensive, non-invasive test for screening and diagnosis could easily be performed in every medical practice leading to an affordable, high-throughput instrument. This review describes recently investigated proteomic screening biomarkers that could improve the early diagnosis of breast cancer in the following years.
\end{abstract}

Keywords Breast cancer Proteomics $\cdot$ Personalized screening $\cdot$ Personalized treatment

\footnotetext{
M. Debald $(\bowtie) \cdot$ M. Wolfgarten $\cdot$ W. Kuhn $\cdot$ M. Braun

Department of Obstetrics and Gynecology,

Center for Integrated Oncology, University of Bonn,

Sigmund-Freud-Str. 25,

53105 Bonn, Germany

e-mail: manuel.debald@ukb.uni-bonn.de

G. Walgenbach-Brünagel

Institute for Clinical Chemistry and Pharmacology, Center for Integrated Oncology, University of Bonn, Bonn, Germany
}

\section{Introduction}

Breast cancer is the most commonly diagnosed type of cancer in women and is responsible for $15 \%$ of cancer related deaths in the United States [1]. Up to now clinical breast examination, imaging by mammography as well as tumor biopsy are the only recommended methods for breast cancer screening in the non-high risk population [2]. A noninvasive test for the early diagnosis of breast cancer would be an efficient step into personalized breast cancer screening and could significantly improve breast cancer survival by bringing the time of diagnosis at an earlier and therefore still curable stage [3,4]. As an early diagnosis is the key for the successful treatment of breast cancer, much effort has been made to develop non-invasive biomarkers for the detection of early-stage breast cancer. But so far there is no reliable non-invasive test available for the clinical routine $[2,5]$.

In this review we would like to give an overview of investigated proteomic screening biomarkers in breast cancer research that could gain success in non-invasive breast cancer screening in the following years.

\section{Non-invasive proteomics}

\section{Protein profiling-methods}

As we know, cancer arises from genetic changes, by which numerous cellular processes such as growth regulation, proliferation and apoptosis are altered [6, 7]. Consequently, first approaches towards cancer-specific biomarkers were based on Genomics and Transcriptomics to get further insights into the genetic basis of cancer development [811]. In the process of developing an individual risk profile 
for the development of breast cancer two breast cancer susceptibility genes BRCA1 and BRCA2 were identified in families with strong patterns of breast cancer $[8,11]$. These two genes are considered to be tumor suppressors and can be found in all women as well as men. Women carrying a mutation in either BRCA1 or BRCA2 are in significantly higher risk of developing breast cancer or ovarian cancer [12]. Thus genetic testing for alterations in BRCA1 and BRCA2 can be used for predicting the individual risk of breast cancer development in patients with familial anamnesis of hereditary breast cancer. Nevertheless, there are major concerns regarding the use of BRCA1 and BRCA2 for genetic testing due to the variability of the eventual onset of breast cancer as well as the final outcome. In addition, women with familial risk without any mutations in BRCA1 or BRCA2 are still at risk of developing breast cancer after a negative testing for one of these genes. Hence, both-negative as well as positive results-may lead to mental distress and concerns regarding further management [13-15]. Alternative splicing of mRNA as well as proteins in combination with the multiplicity of post-translational alterations such as phosphorylation, ubiquitination or nitration explain why one single gene code for different protein species [16, 17]. Thus, Genetics by itself shows just an incomplete pattern of cancer development, whereas Proteomics reflects the genetic program of each cell as well as its final influence on the cellular physiology in a more dynamic way $[18,19]$.

The quest for screening biomarkers in cancer was initially based on two-dimensional gel electrophoresis (Fig. 1) [20]. Thereby specific protein fingerprints in malignant conditions are detected by their apparent molecular mass and isoelectric point. For protein detection the electrophoretically separated polypeptides are visualized by sensitive staining methods such as silver staining. In a further step the patterns of patients' samples and healthy controls are screened for differences in protein patterns. The spots of interest are excised from the gel, subjected to

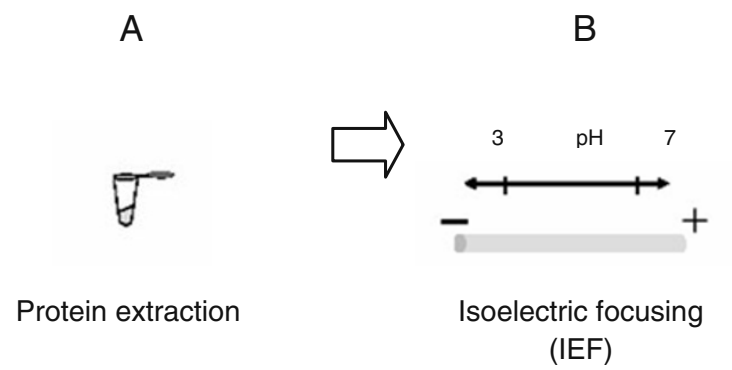

Fig. 1 Protein identification by two-dimensional gel electrophoresis (2D-PAGE). A: Protein extraction of patients' samples and healthy controls. B: By isoelectric focusing (IEF) proteins are separated on their isoelectric point $(\mathrm{pI})$ in a strong electric field using stripes with an immobilized $\mathrm{pH}$ gradient (IPG-Stripe). C: After IEF an electric potential is applied to the IPG-Stripe at a 90 degree angle from the protease digestion by what peptide fragments can be examined in further analyses. Nevertheless, it is a time consuming process that is difficult to automate and to reproduce. Furthermore, it cannot adequately resolve the large number of protein modifications within a tumor sample.

Later on, advances in analytical technologies regarding mass spectroscopy (MS) facilitated large-scale proteomic analyses (Fig. 2) [21]. MS measures the mass to charge ratio $(\mathrm{m} / \mathrm{z})$ of ionized proteins as they travel through an electric or a magnetic field. Proteins are analyzed and identified based on unique spectrometric signatures, which reveals even structural features such as phosphorylation or methylation.

\section{Blood-based protein profiling}

Reflecting the physiological and pathological status of the human body in combination with its easy collection and availability blood represents the most extensively studied substance in the search of cancer biomarkers [22]. Specific tumor-secreted proteins in conjunction with cancer related patterns of digested tissue and plasma proteins make blood the ideal source for proteomic analyses [18, 23].

Numerous serum- and plasma-based SELDI-TOF MS and MALDI-TOF MS analyses were performed during the last years to differentiate between breast cancer patients, benign disease and healthy controls [24-27]. Each study described specific patterns of protein peaks, whereas all of them kept structurally unidentified and their validation in an independent sample set is still outstanding. Contrariwise, $\mathrm{Li}$ et al. screened the serum of 103 stage I-III breast cancer patients, 25 benign controls as well as 41 healthy women and verified two increased peaks $(8.1 \mathrm{kDa}, 8.9 \mathrm{kDa})$ as well as one decreased peak $(4.3 \mathrm{kDa})$ in the serum of breast cancer patients which have been structurally identified as the $\mathrm{C}$-terminal truncated form of complement component $\mathrm{C} 3 \mathrm{a}(\mathrm{CtC} 3 \mathrm{a}, 8.1 \mathrm{kDa})$, complement component $\mathrm{C} 3 \mathrm{a}$ itself

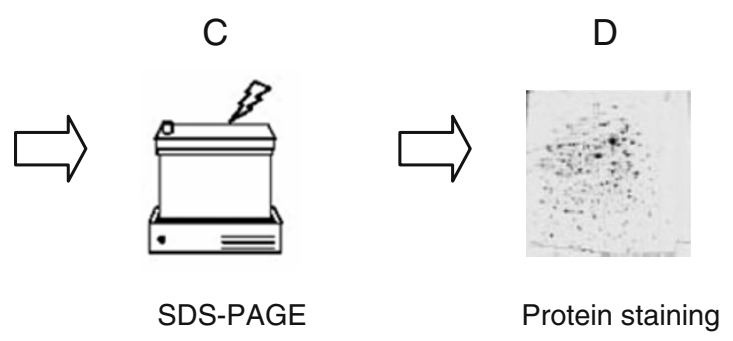

first field and proteins are separated by sodium dodecylsulfate polyacrylamide gel electrophoresis (SDS-PAGE). The gel acts as a molecular sieve by separating the proteins on the basis of their relative molecular mass. D: Proteins are visualized by sensitive staining methods such as silver staining 


\section{A}

1 sample fractionation

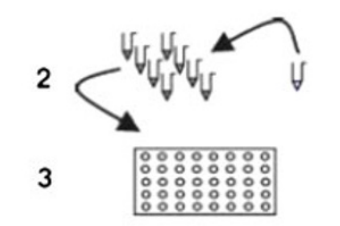

B

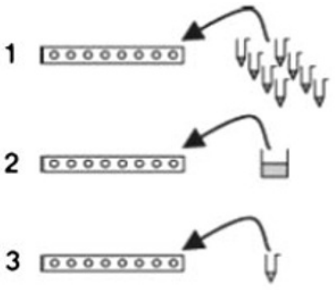

C

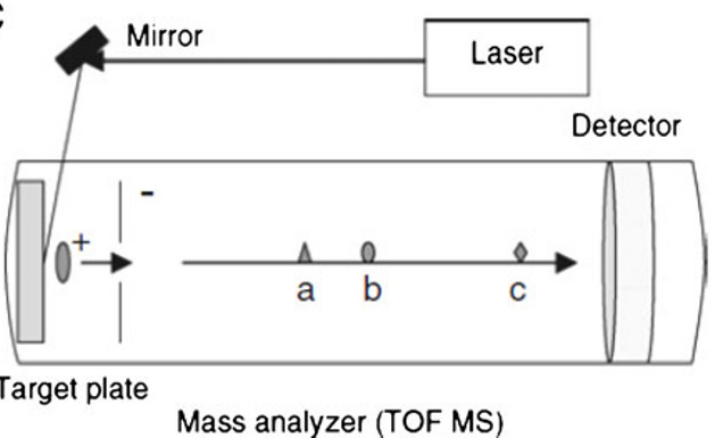

D

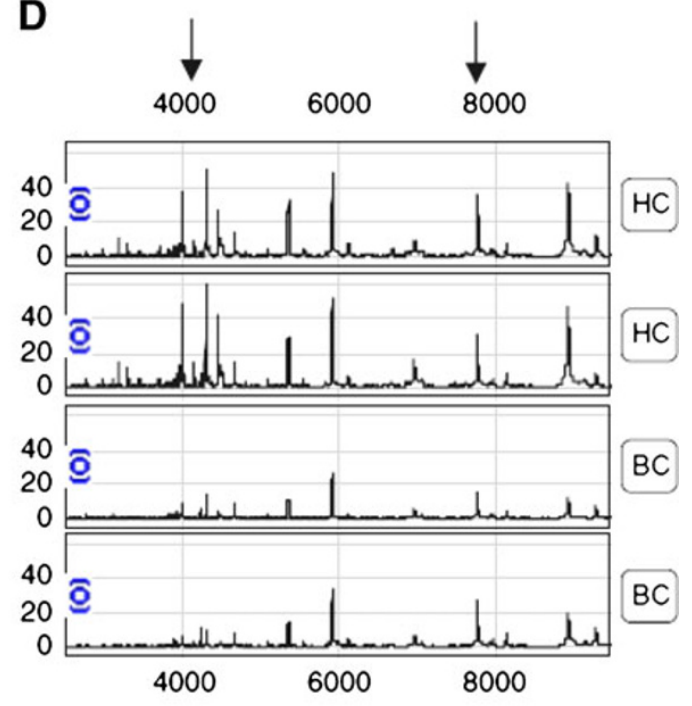

Fig. 2 Schematic demonstration of MALDI- and SELDI-TOF MS (adapted from [20]). A1-A3: Performing matrix-assisted laser desorption/ionization-time of flight mass spectrometry (MALDI-TOF MS) the samples are fractionated off-line using chromatographic beads. An energy absorbing matrix e.g. cinnamic acid is added to the fractionated samples and this mix is applicated to an inert plate for laser desorption/ionization in a time of flight (TOF) mass analyzer (C). B1-B3: For surface-enhanced laser desorption/ionization-time of flight mass spectrometry (SELDI-TOF MS) the sample is loaded onto a protein-selective array with a hydrophilic, hydrophobic, cationic, anionic or immobilized-metal affinity capture moiety in an appropriate binding buffer. The sample is purified by one or more washing steps

$(8.9 \mathrm{kDa})$ and a fragment of inter-alpha-trypsin inhibitor heavy chain H4 (ITIH4, $4.3 \mathrm{kDa})[28,29]$. In a further independent sample set only the C-terminal truncated form of complement component $\mathrm{C} 3 \mathrm{a}(8.1 \mathrm{kDa})$ and complement component $\mathrm{C} 3 \mathrm{a}(8.9 \mathrm{kDa})$ could be verified, whereas the $8.1 \mathrm{kDa}$-fragment also lost its significance in further validation [29-31]. In comparable studies the decreased ITIH4-fragment at $4.3 \mathrm{kDa}$ was found to be increased in the serum of breast cancer patients or even lost its ability to distinguish between cancer patients and healthy controls [32-34]. Due to the inhomogeneous results regarding ITIH4 and the C3-complement components described above, which have recently been reconfirmed to be upregulated in breast cancer patients, the diagnostic strength of these markers can not be finally evaluated yet [35]. Fan et al. described also a down-regulated candidate protein $(6.6 \mathrm{kDa})$, which was identified as apolipoprotein $\mathrm{C}-1$ (APO-C1) that might play a certain role in breast cancer carcinogenesis [35]. Further candidate biomarkers of the lipoprotein-group (APO A-IV) had also been described by Villanueva et al. before, whereas these findings as well as the diagnostic power of further candidate markers such as fibrinogen alpha, bradykinin, factor XIII or transthyretin and the bound proteins are treated with an energy-absorbing matrix such as cinnamic acid for desorption/ionization by laser in a TOF mass analyzer (C). C: The MALDI target plate or SELDI array is inserted into the analyzer, where bound proteins are treated with laser irradiation for desorption and ionization. Owing to the electric field, they are accelerated through a TOF-analyzer and separated by a mass per charge ratio $(\mathrm{m} / \mathrm{z})$ : small proteins $(\mathrm{c})$ migrate faster than multiply charged (b) or large ones (a). D: In a resulting mass spectrum the $\mathrm{m} / \mathrm{z}$ ratio is displayed on the $\mathrm{x}$-axis, whereas the $\mathrm{y}$-axis reflects the protein abundance. Here, SELDI-TOF MS shows up-regulations in the serum of breast cancer patients (BC) compared to healthy controls (HC) are visible at m/z 3980, m/z 4292 and m/z 8939

have to be validated in larger studies before their future clinical implementation [34]. In a pathology-specific blood proteome analysis by Braun et al. expression patterns of circulating leucokytes were investigated in breast cancer patients, patients with benign tumors and healthy controls [36]. Performing protein mapping this group demonstrated significant alterations in the repertoire of microfilamental network-associated proteins in circulating leukocytes of breast cancer patients compared to healthy controls: Calgranulin A (S100), LyGDI (RhoGDI $\beta$ ), RhoA and profilin 1. Investigating cellular subfractions by twodimensional gel electrophoresis (2D-PAGE), nuclear matrix proteins (NMP) have been shown to be cell and cancer specific [37-40]. Hence, circulating NMP are ideal candidates for non-invasive cancer diagnosis in several cancer entities [41-43]. Unlike established protocols of separating NMP by two-dimensional gel electrophoresis, NMP66 $(28.3 \mathrm{kDa})$ was found to be specific for breast cancer by a serum proteomic screening strategy using SELDI-TOF MS [44]. But up to now NMP66 did not make its way to clinical routine. Based on our expertise with CCSA-2 in the development of a serum-based immunoassay in colon cancer we are investigating the use of NMP in breast 
Discomfort scale

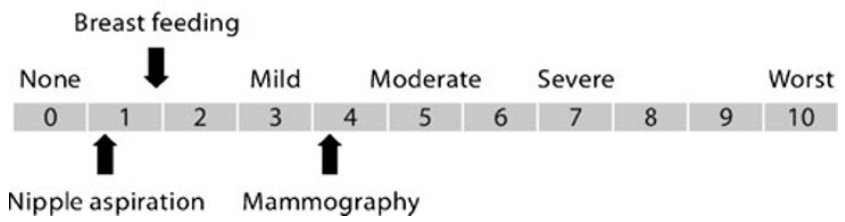

Fig. 3 Discomfort of nipple aspiration in comparison with mammography and breast feeding in a study on female healthy volunteers [48]

cancer by two-dimensional gel electrophoresis in an ongoing study [43].

Diagnostic proteomics in nipple aspiration

Nipple fluid, that contains breast epithelial cells, is produced in the breast ducts and can be collected by vacuum aspiration or ductal lavage. Based on the idea that the concentrated source of proteins from breast cancer ducts might be better able to identify tumor-specific protein patterns, attention has been paid to the proteomic analysis of nipple aspiration fluid (NAF) and ductal lavage fluid (DLF). Performing SELDITOF MS of 114 NAF-samples obtained from 27 breast cancer patients and 87 healthy controls Sauter et al. defined a $11.8 \mathrm{kDa}$ protein that appeared to be specific for breast cancer patients [45]. Pawlik et al. employed the use of SELDI-TOF MS to NAF in 23 women with stage I and II breast cancer to compare them to 5 healthy volunteers [46]. In this study 17 peaks were overexpressed in cancer-bearing breasts compared to breasts of healthy controls $(p<0.0005)$. When spectra from the nontumor-bearing breasts of breast cancer patients were compared with spectra from breasts of healthy controls, two distinct peaks were noted to be overexpressed in breast cancer patients and one peak was underexpressed $(p<0.0027)$. These results get support from Noble et al. who found nine protein peaks to be significantly different between the cancer-bearing breast compared with healthy women as well as 10 peaks of the contralateral healthy breast and healthy women $(p<0.05)$ [47]. Performing twodimensional gel electrophoretic separation and MALDITOF analysis in 20 NAF-samples of 10 breast cancer patients and 10 healthy controls Alexander et al. distinguished between three peaks that were up-regulated in three or more breast cancer patients [48]. These peaks were identified as gross cystic disease fluid protein-15 (GCDFB15), apolipoprotein-D (apo-D) and alpha-1-acid glycoprotein (AAG). For further validation $105 \mathrm{NAF-samples} \mathrm{(52}$ cancerous and 53 controls) were analyzed by ELISA, whereas GCDFB-15 levels were showed to be lower ( $p<$ $0.001)$ and AAG levels to be higher $(p<0.001)$ in breast cancer patients. Apo-D levels were not associated with breast cancer in this control.

Based on recent findings of Suijkerbuijk et al., who described the advantages of Oxytocin-supported nipple aspiration affiliated with reduced discomfort (Fig. 3), NAF might be a promising instrument for breast cancer diagnosis and should be validated in further studies [49].

\section{Salivary protein profiling}

Saliva is the secretion of the salivary glands representing a source of easily accessible body fluids. In 1999 the use of saliva for diagnostic purposes has been demonstrated by the detection of elevated levels of CA15.3 and c-erB-2 in breast cancer patients [50]. Inspired by the absolute non-invasive character as well as the ease of sample handling Steckfus et al. investigated the feasibility of salivary protein profiling for diagnostic purposes in breast cancer [51]. Using SELDITOF MS five high molecular weight peaks were found to be overexpressed in breast cancer patients compared to healthy controls. Although these peaks were never structurally identified this group was able to demonstrate the potential use of saliva for breast cancer diagnosis. Recently, the initial findings were supported by salivary protein profiles that are unique to fibroadenoma and ductual carcinoma in-situ of the breast [52].
Fig. 4 False-negative mediolateral oblique mammogram of a 50 years old female patient in routine breast cancer screening (a). The additional Breast-MRI (b) identifies two small enhancing foci (arrows). MR-guided biopsy revealed multifocal ductal invasive breast cancer
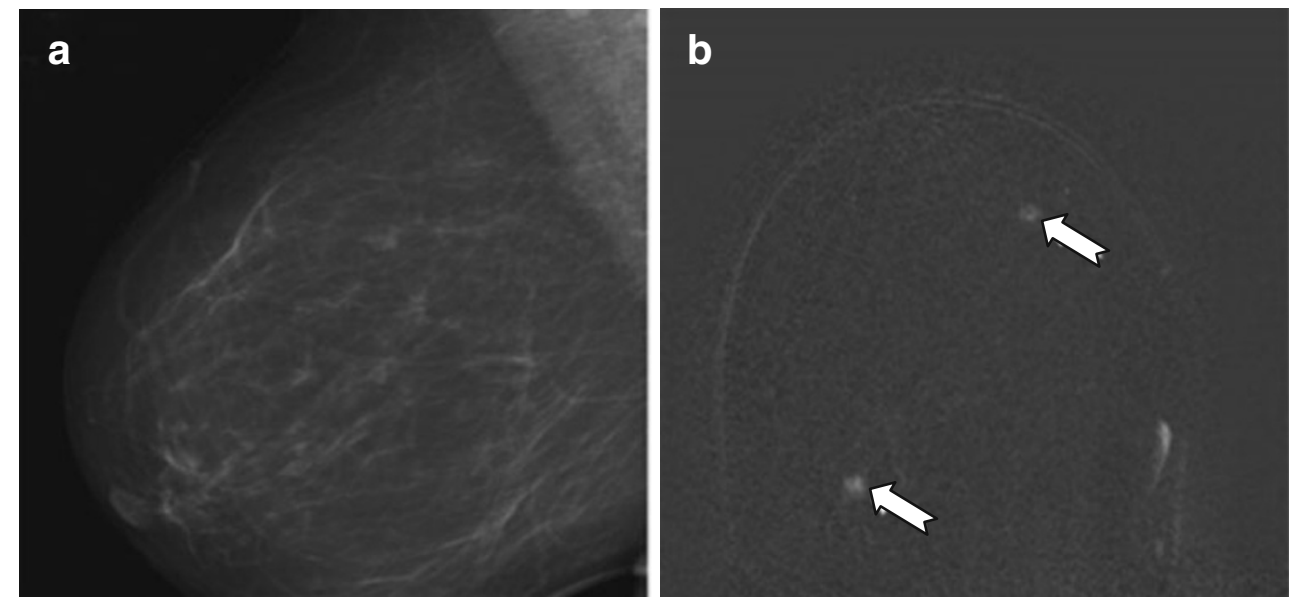


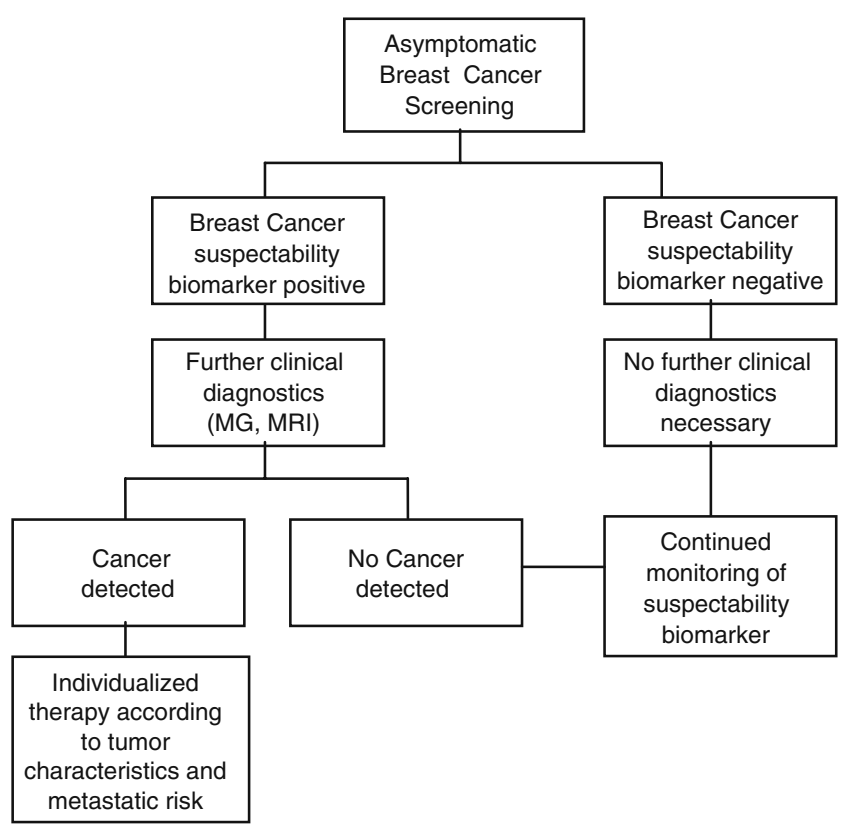

Fig. 5 Flow-chart: Personalized Screening for breast cancer using a screening biomarker as gatekeeper before further clinical diagnostics

\section{Potential behind non-invasive diagnostic technologies}

The early diagnosis of breast cancer in a potentially curable stage improves the prognosis and consecutively reduces mortality of breast cancer patients [3, 4]. The established screening by breast examination and mammography is able to detect breast cancer in early stages and has been shown to reduce mortality $[53,54]$. Nevertheless, screening by mammography is controversially discussed due to significant rates of false negative results (Fig. 4) as well as false positive results leading to overdiagnosis and overtherapy [55]. Especially young women ( $<50$ years) with high breast density show low sensitivities in mammography, wherefore established mammography screening programs are mainly addressed to older patients (50-69 years) [56, 57]. Keeping in mind that 1 of 5 breast cancers occurs in this non-screened subgroup and these patients suffer from more aggressive and fast growing forms of breast cancer the proposed non-invasive screening biomarker would be of outstanding value [58, 59].

Thus it is necessary to implement a reliable non-invasive test as a gatekeeper for further diagnostics among asymptomatic patients (Fig. 5). In a second step only patients with a positive breast-cancer-suspectability-biomarker would receive further imaging or biopsy. Asymptomatic patients showing a negative breast-cancer-suspectability-biomarker are not in need of additional clinical diagnostics and are spared uncertainties and anxiety due to ambiguous imaging results. Table 1 summarizes candidate non-invasive proteomic biomarkers that could improve the early diagnosis of breast cancer in the following years.
Table 1 Non-invasive Proteomic biomarkers for breast cancer discussed in this review

\begin{tabular}{lll}
\hline Medium & Biomarker & Profiling method \\
\hline Serum & C3a & SELDI-TOF MS \\
Serum & CtC3a & SELDI-TOF MS \\
Serum & ITIH4 & SELDI-TOF MS \\
Serum & APO-C1 & SELDI-TOF MS \\
Serum & APO A-IV & MALDI-TOF MS \\
Serum & Fibrinogen alpha & MALDI-TOF MS \\
Serum & Bradykinin & MALDI-TOF MS \\
Serum & Factor XIII & MALDI-TOF MS \\
Serum & Transthyretin & MALDI-TOF MS \\
Blood (Leukocytes) & Calgranulin A & 2D-PAGE, MALDI-TOF MS \\
Blood (Leukocytes) & LyGDI (RhoGDI $\beta$ ) & 2D-PAGE, MALDI-TOF MS \\
Blood (Leukocytes) & RhoA & 2D-PAGE, MALDI-TOF MS \\
Blood (Leukocytes) & Profilin 1 & 2D-PAGE, MALDI-TOF MS \\
Serum & NMP66 & SELDI-TOF MS \\
Nipple fluid & 11.8 kDa peak (structurally unidentified) & SELDI-TOF MS \\
Nipple fluid & GCDFB-15 & 2D-PAGE, MALDI-TOF MS \\
Nipple fluid & APO-D & 2D-PAGE, MALDI-TOF MS \\
Nipple fluid & AAG & 2D-PAGE, MALDI-TOF MS \\
Saliva & 18 kDa peak (structurally unidentified) & SELDI-TOF MS \\
Saliva & 113 kDa peak (structurally unidentified) & SELDI-TOF MS \\
Saliva & $170 \mathrm{kDa}$ peak (structurally unidentified) & SELDI-TOF MS \\
Saliva & $228 \mathrm{kDa}$ peak (structurally unidentified) & SELDI-TOF MS \\
Saliva & 287 kDa peak (structurally unidentified) & SELDI-TOF MS \\
\hline & & \\
\hline & & \\
\hline & & \\
\hline & & \\
\hline
\end{tabular}




\section{Clinical impact of predictive medicine in breast cancer treatment}

In a further step towards personalized medicine recent biomarker developments regarding innate tumor characteristics could contribute to a more individualized breast cancer management. It has been shown that each tumor presents unique characteristics with different outcomes, relapse and responsiveness to therapy [60-62]. Traditionally, breast cancer prognosis was determined by clinical as well as histopathological features such as age, tumor size, lymph node status, grading, hormone receptor status and Her2/neu status [63-65]. Recently, these traditional factors have been completed by multi gene expression tools like Mammaprint, Oncotype DX or Rotterdam Signature that can be used to predict the risk of recurrence or distant metastases in nodenegative disease $[9,10,66-68]$. In patients with newly diagnosed node-negative breast cancer urokinase plasminogen activator (UPA) and plasminogen activator inhibitor 1 (PAI-1) might be used for prognostic evaluation as well [69]. It has been shown that elevated levels of both factors, uPA and PAI-1, in tumor tissue are associated with a higher risk of recurrence and death, wherefore especially these patients may benefit from adjuvant treatment [70-72]. Another target of individualized breast cancer management should be residing on predictive biomarkers determining the response to certain adjuvant regimes in a particular patient. It is known that Anthracycline-based treatment alone as well as in combination with Taxanes shows significant benefits in patients with lymph node-positive breast cancer and Her2/ neu-overexpression [73-75]. Further factors like Topoisomerase II-overexpression, which suggests greater benefit from Anthracycline-based chemotherapy, or low expression of Microtubule-associated protein tau, which is associated with increased chemosensitivity to Taxanes, are under ongoing investigation [76-78]. Contrariwise, high levels of Tau correlate with estrogen receptor (ER)-positive breast cancer and may predict endocrine sensitivity in this subgroup of patients [79]. Consequentially, an increased expression of Microtubule-associated protein tau may define ER-positive breast cancers with increased sensitivity to endocrine therapy, whereas lower Tau levels may indicate better chemosensitivity to Taxanes ER-positive breast cancer patients [80].

\section{Outlook}

Biomarkers that detect cancer, predict cancer outcome and influence treatment choices will play a major role in the future management of breast cancer. The proposed combination of an objective breast-cancer-suspectabilitybiomarker with established clinical diagnostics could help to increase the acceptance of population based breast cancer screening programs by creating an individual risk profile, which is irrespective of mammography quality and interpretation. A simple, robust and inexpensive, non-invasive test for screening and diagnosis could easily be performed in every medical practice leading to an affordable, highthroughput instrument. Recent technological improvements to identify and characterize proteins by two-dimensional gel-electrophoresis and mass spectroscopy in combination with improved bioinformatical databases and analysis software make Proteomics a powerful tool in the quest for new tumor markers. Thus, outmost effort should be put into the development, validation and clinical implementation of reliable screening biomarkers.

Acknowledgement Manuel Debald is funded by BONFOR, University of Bonn.

\section{References}

1. Jemal A, Siegel R, Ward E, Hao Y, Xu J, Thun MJ. Cancer statistics, 2009. CA Cancer J Clin. 2009;59:225-49.

2. Smith RA, Cokkinides V, Brooks D, Saslow D, Brawley OW. Cancer screening in the United States, 2010: a review of current American Cancer Society guidelines and issues in cancer screening. CA Cancer J Clin. 2010;60:99-119.

3. Arriagada R, Rutqvist LE, Johansson H, Kramar A, Rotstein S. Predicting distant dissemination in patients with early breast cancer. Acta Oncol. 2008;47:1113-21.

4. Cianfrocca M, Goldstein LJ. Prognostic and predictive factors in early-stage breast cancer. Oncologist. 2004;9:606-16.

5. Harris L, Fritsche H, Mennel R, Norton L, Ravdin P, Taube S, et al. American Society of Clinical Oncology 2007 update of recommendations for the use of tumor markers in breast cancer. J Clin Oncol. 2007;25:5287-312.

6. Mommers EC, van Diest PJ, Leonhart AM, Meijer CJ, Baak JP. Balance of cell proliferation and apoptosis in breast carcinogenesis. Breast Cancer Res Treat. 1999;58:163-9.

7. Reis-Filho JS, Lakhani SR. The diagnosis and management of pre-invasive breast disease: genetic alterations in pre-invasive lesions. Breast Cancer Res. 2003;5:313-9.

8. Miki Y, Swensen J, Shattuck-Eidens D, Futreal PA, Harshman K, Tavtigian S, et al. A strong candidate for the breast and ovarian cancer susceptibility gene BRCA1. Science. 1994;266:66-71.

9. van't Veer LJ, Dai H, van de Vijver MJ, He YD, Hart AA, Mao $\mathrm{M}$, et al. Gene expression profiling predicts clinical outcome of breast cancer. Nature. 2002;415:530-6.

10. Wang Y, Klijn JG, Zhang Y, Sieuwerts AM, Look MP, Yang F, et al. Gene-expression profiles to predict distant metastasis of lymphnode-negative primary breast cancer. Lancet. 2005;365:671-9.

11. Wooster R, Bignell G, Lancaster J, Swift S, Seal S, Mangion J, et al. Identification of the breast cancer susceptibility gene BRCA2. Nature. 1995;378:789-92.

12. Ford D, Easton DF, Stratton M, Narod S, Goldgar D, Devilee P. Genetic heterogeneity and penetrance analysis of the BRCA1 and BRCA2 genes in breast cancer families. The Breast Cancer Linkage Consortium. Am J Hum Genet. 1998;62:676-89.

13. Foster C, Evans DG, Eeles R, Eccles D, Ashley S, Brooks L, et al. Predictive testing for BRCA1/2: attributes, risk perception and management in a multi-centre clinical cohort. $\mathrm{Br} \mathrm{J}$ Cancer. 2002;86:1209-16. 
14. Michelsen TM, Dorum A, Dahl AA. A controlled study of mental distress and somatic complaints after risk-reducing salpingooophorectomy in women at risk for hereditary breast ovarian cancer. Gynecol Oncol. 2009;113:128-33.

15. van Oostrom I, Meijers-Heijboer H, Lodder LN, Duivenvoorden HJ, van Gool AR, Seynaeve C, et al. Long-term psychological impact of carrying a BRCA $1 / 2$ mutation and prophylactic surgery: a 5-year follow-up study. J Clin Oncol. 2003;21:3867-74.

16. Banks RE, Dunn MJ, Hochstrasser DF, Sanchez JC, Blackstock W, Pappin DJ, et al. Proteomics: new perspectives, new biomedical opportunities. Lancet. 2000;356:1749-56.

17. Azad NS, Rasool N, Annunziata CM, Minasian L, Whiteley G, Kohn EC. Proteomics in clinical trials and practice: present uses and future promise. Mol Cell Proteomics. 2006;5:1819-29.

18. Aebersold R, Anderson L, Caprioli R, Druker B, Hartwell L, Smith R. Perspective: a program to improve protein biomarker discovery for cancer. J Proteome Res. 2005;4:1104-9.

19. Dove A. Proteomics: translating genomics into products? Nat Biotechnol. 1999;17:233-6.

20. Hondermarck H, Vercoutter-Edouart AS, Revillion F, Lemoine J, el-Yazidi-Belkoura I, Nurcombe V, et al. Proteomics of breast cancer for marker discovery and signal pathway profiling. Proteomics. 2001;1:1216-32.

21. Engwegen JY, Gast MC, Schellens JH, Beijnen JH. Clinical proteomics: searching for better tumour markers with SELDI-TOF mass spectrometry. Trends Pharmacol Sci. 2006;27:251-9.

22. Hanash SM, Pitteri SJ, Faca VM. Mining the plasma proteome for cancer biomarkers. Nature. 2008;452:571-9.

23. Conrads TP, Zhou M, Petricoin III EF, Liotta L, Veenstra TD. Cancer diagnosis using proteomic patterns. Expert Rev Mol Diagn. 2003;3:411-20.

24. Callesen AK, Vach W, Jorgensen PE, Cold S, Tan Q, Depont CR, et al. Combined experimental and statistical strategy for mass spectrometry based serum protein profiling for diagnosis of breast cancer: a case-control study. J Proteome Res. 2008;7:1419-26.

25. De Noo ME, Deelder A, van der Werff M, Ozalp A, Mertens B, Tollenaar R. MALDI-TOF serum protein profiling for the detection of breast cancer. Onkologie. 2006;29:501-6.

26. Hu Y, Zhang S, Yu J, Liu J, Zheng S. SELDI-TOF-MS: the proteomics and bioinformatics approaches in the diagnosis of breast cancer. Breast. 2005;14:250-5.

27. Shin S, Cazares L, Schneider H, Mitchell S, Laronga C, Semmes OJ, et al. Serum biomarkers to differentiate benign and malignant mammographic lesions. J Am Coll Surg. 2007;204:1065-71.

28. Li J, Zhang Z, Rosenzweig J, Wang YY, Chan DW. Proteomics and bioinformatics approaches for identification of serum biomarkers to detect breast cancer. Clin Chem. 2002;48:1296-304.

29. Li J, Orlandi R, White CN, Rosenzweig J, Zhao J, Seregni E, et al. Independent validation of candidate breast cancer serum biomarkers identified by mass spectrometry. Clin Chem. 2005;51:2229-35.

30. Mathelin C, Cromer A, Wendling C, Tomasetto C, Rio MC. Serum biomarkers for detection of breast cancers: a prospective study. Breast Cancer Res Treat. 2006;96:83-90.

31. van Winden AW, Gast MC, Beijnen JH, Rutgers EJ, Grobbee DE, Peeters $\mathrm{PH}$, et al. Validation of previously identified serum biomarkers for breast cancer with SELDI-TOF MS: a case control study. BMC Med Genomics. 2009;2:4.

32. Fung ET, Yip TT, Lomas L, Wang Z, Yip C, Meng XY, et al. Classification of cancer types by measuring variants of host response proteins using SELDI serum assays. Int $\mathrm{J}$ Cancer. 2005;115:783-9.

33. Song J, Patel M, Rosenzweig CN, Chan-Li Y, Sokoll LJ, Fung ET, et al. Quantification of fragments of human serum inter-alpha-trypsin inhibitor heavy chain 4 by a surface-enhanced laser desorption/ ionization-based immunoassay. Clin Chem. 2006;52:1045-53.
34. Villanueva J, Shaffer DR, Philip J, Chaparro CA, ErdjumentBromage $\mathrm{H}$, Olshen $\mathrm{AB}$, et al. Differential exoprotease activities confer tumor-specific serum peptidome patterns. J Clin Invest. 2006;116:271-84.

35. Fan Y, Wang J, Yang Y, Liu Q, Fan Y, Yu J, Zheng S, Li M, Wang J. Detection and identification of potential biomarkers of breast cancer. J Cancer Res Clin Oncol. 2010 (Epub ahead of print).

36. Braun M, Fountoulakis M, Papadopoulou A, Vougas K, Seidel I, Holler $\mathrm{T}$, et al. Down-regulation of microfilamental networkassociated proteins in leukocytes of breast cancer patients: potential application to predictive diagnosis. Cancer Genomics Proteomics. 2009;6:31-40.

37. Brunagel G, Vietmeier BN, Bauer AJ, Schoen RE, Getzenberg $\mathrm{RH}$. Identification of nuclear matrix protein alterations associated with human colon cancer. Cancer Res. 2002;62:2437-42.

38. Getzenberg RH, Pienta KJ, Huang EY, Coffey DS. Identification of nuclear matrix proteins in the cancer and normal rat prostate. Cancer Res. 1991;51:6514-20.

39. Getzenberg RH, Konety BR, Oeler TA, Quigley MM, Hakam A, Becich $\mathrm{MJ}$, et al. Bladder cancer-associated nuclear matrix proteins. Cancer Res. 1996;56:1690-4.

40. Konety BR, Nangia AK, Nguyen TS, Veitmeier BN, Dhir R, Acierno JS, et al. Identification of nuclear matrix protein alterations associated with renal cell carcinoma. J Urol. 1998;159:1359-63.

41. Paul B, Dhir R, Landsittel D, Hitchens MR, Getzenberg RH. Detection of prostate cancer with a blood-based assay for early prostate cancer antigen. Cancer Res. 2005;65:4097-100.

42. Van Le TS, Miller R, Barder T, Babjuk M, Potter DM, Getzenberg RH. Highly specific urine-based marker of bladder cancer. Urology. 2005;66:1256-60.

43. Walgenbach-Brunagel G, Burger B, Leman ES, Walgenbach KJ, Tolba R, Heukamp L, et al. The use of a colon cancer associated nuclear antigen CCSA-2 for the blood based detection of colon cancer. J Cell Biochem. 2008;104:286-94.

44. Luftner D, Possinger K. Nuclear matrix proteins as biomarkers for breast cancer. Expert Rev Mol Diagn. 2002;2:23-31.

45. Sauter ER, Shan S, Hewett JE, Speckman P, Du Bois GC. Proteomic analysis of nipple aspirate fluid using SELDI-TOF-MS. Int J Cancer. 2005;114:791-6.

46. Pawlik TM, Fritsche H, Coombes KR, Xiao L, Krishnamurthy S, Hunt KK, et al. Significant differences in nipple aspirate fluid protein expression between healthy women and those with breast cancer demonstrated by time-of-flight mass spectrometry. Breast Cancer Res Treat. 2005;89:149-57.

47. Noble JL, Dua RS, Coulton GR, Isacke CM, Gui GP. A comparative proteinomic analysis of nipple aspiration fluid from healthy women and women with breast cancer. Eur J Cancer. 2007;43:2315-20.

48. Alexander H, Stegner AL, Wagner-Mann C, Du Bois GC, Alexander S, Sauter ER. Proteomic analysis to identify breast cancer biomarkers in nipple aspirate fluid. Clin Cancer Res. 2004;10:7500-10.

49. Suijkerbuijk KP, van der Wall E, van Diest PJ. Oxytocin: bringing magic into nipple aspiration. Ann Oncol. 2007;18:1743-4.

50. Streckfus C, Bigler L, Dellinger T, Pfeifer M, Rose A, Thigpen JT. CA 15-3 and c-erbB-2 presence in the saliva of women. Clin Oral Investig. 1999;3:138-43.

51. Streckfus CF, Bigler LR, Zwick M. The use of surface-enhanced laser desorption/ionization time-of-flight mass spectrometry to detect putative breast cancer markers in saliva: a feasibility study. J Oral Pathol Med. 2006;35:292-300.

52. Streckfus CF, Mayorga-Wark O, Arreola D, Edwards C, Bigler L, Dubinsky WP. Breast cancer related proteins are present in saliva and are modulated secondary to ductal carcinoma in situ of the breast. Cancer Investig. 2008;26:159-67. 
53. Coldman A, Phillips N, Warren L, Kan L. Breast cancer mortality after screening mammography in British Columbia women. Int $\mathbf{J}$ Cancer. 2007;120:1076-80.

54. Tabar L, Yen MF, Vitak B, Chen HH, Smith RA, Duffy SW. Mammography service screening and mortality in breast cancer patients: 20-year follow-up before and after introduction of screening. Lancet. 2003;361:1405-10.

55. Jorgensen KJ, Gotzsche PC. Overdiagnosis in publicly organised mammography screening programmes: systematic review of incidence trends. BMJ. 2009;339:b2587.

56. Buist DS, Porter PL, Lehman C, Taplin SH, White E. Factors contributing to mammography failure in women aged 40-49 years. J Natl Cancer Inst. 2004;96:1432-40.

57. Schopper D, de Wolf C. How effective are breast cancer screening programmes by mammography? Review of the current evidence. Eur J Cancer. 2009;45:1916-23.

58. Brekelmans CT, van Gorp JM, Peeters PH, Collette HJ. Histopathology and growth rate of interval breast carcinoma. Characterization of different subgroups. Cancer. 1996;78:1220-8.

59. Braun M, Fountoulakis M, Yeghiazaryan K, Schild HH, Kuhn W, Golubnitschaja O. How realistic are non-invasive approaches in breast cancer prediction? In: Golubnitschaja O, editor. Predictive diagnostics and personalized treatment: dream or reality? New York: Nova Science Publishers; 2009.

60. Hanash S. Integrated global profiling of cancer. Nat Rev Cancer. 2004;4:638-44.

61. Classen S, Muth C, Debey-Pascher S, Eggle D, Beyer M, Mallmann MR, et al. Application of T cell-based transcriptomics to identify three candidate biomarkers for monitoring antiTGFbetaR therapy. Pharmacogenet Genomics. 2010;20:147-56.

62. Yeghiazaryan K, Braun M, Mangion J, Mamlouk S, Schild HH, Golubnitschaja O. Are side-effects of irradiation predictable for treatment of breast cancer patients? In: Golubnitschaja O, editor. Predictive diagnostics and personalized treatment: dream or reality? New York: Nova Science Publishers; 2009.

63. Carter CL, Allen C, Henson DE. Relation of tumor size, lymph node status, and survival in 24, 740 breast cancer cases. Cancer. 1989;63:181-7.

64. Galea MH, Blamey RW, Elston CE, Ellis IO. The Nottingham Prognostic Index in primary breast cancer. Breast Cancer Res Treat. 1992;22:207-19.

65. Press MF, Bernstein L, Thomas PA, Meisner LF, Zhou JY, Ma Y, et al. HER-2/neu gene amplification characterized by fluorescence in situ hybridization: poor prognosis in node-negative breast carcinomas. J Clin Oncol. 1997;15:2894-904.

66. van de Vijver MJ, He YD, van't Veer LJ, Dai H, Hart AA, Voskuil $\mathrm{DW}$, et al. A gene-expression signature as a predictor of survival in breast cancer. N Engl J Med. 2002;347:1999-2009.

67. Cronin M, Pho M, Dutta D, Stephans JC, Shak S, Kiefer MC, et al. Measurement of gene expression in archival paraffinembedded tissues: development and performance of a 92-gene reverse transcriptase-polymerase chain reaction assay. Am J Pathol. 2004;164:35-42.
68. Foekens JA, Atkins D, Zhang Y, Sweep FC, Harbeck N, Paradiso A, et al. Multicenter validation of a gene expression-based prognostic signature in lymph node-negative primary breast cancer. J Clin Oncol. 2006;24:1665-71.

69. Duffy MJ. Urokinase plasminogen activator and its inhibitor, PAI1 , as prognostic markers in breast cancer: from pilot to level 1 evidence studies. Clin Chem. 2002;48:1194-7.

70. Harbeck N, Kates RE, Look MP, Meijer-van Gelder ME, Klijn JG, Kruger A. Enhanced benefit from adjuvant chemotherapy in breast cancer patients classified high-risk according to urokinasetype plasminogen activator (uPA) and plasminogen activator inhibitor type $1(\mathrm{n}=3424)$. Cancer Res. 2002;62:4617-22.

71. Harbeck N, Schmitt M, Kates RE, Kiechle M, Zemzoum I, Janicke F, et al. Clinical utility of urokinase-type plasminogen activator and plasminogen activator inhibitor-1 determination in primary breast cancer tissue for individualized therapy concepts. Clin Breast Cancer. 2002;3:196-200.

72. Janicke F, Prechtl A, Thomssen C, Harbeck N, Meisner C, Untch $\mathrm{M}$, et al. Randomized adjuvant chemotherapy trial in high-risk, lymph node-negative breast cancer patients identified by urokinase-type plasminogen activator and plasminogen activator inhibitor type 1. J Natl Cancer Inst. 2001;93:913-20.

73. Hayes DF, Thor AD, Dressler LG, Weaver D, Edgerton S, Cowan $\mathrm{D}$, et al. HER2 and response to paclitaxel in node-positive breast cancer. N Engl J Med. 2007;357:1496-506.

74. Paik S, Bryant J, Park C, Fisher B, Tan-Chiu E, Hyams D, et al. erbB-2 and response to doxorubicin in patients with axillary lymph node-positive, hormone receptor-negative breast cancer. J Natl Cancer Inst. 1998;90:1361-70.

75. Thor AD, Berry DA, Budman DR, Muss HB, Kute T, Henderson IC, et al. erbB-2, p53, and efficacy of adjuvant therapy in lymph node-positive breast cancer. J Natl Cancer Inst. 1998;90:1346-60.

76. Burgess DJ, Doles J, Zender L, Xue W, Ma B, McCombie WR, et al. Topoisomerase levels determine chemotherapy response in vitro and in vivo. Proc Natl Acad Sci USA. 2008;105:9053-8.

77. Jarvinen TA, Tanner M, Rantanen V, Barlund M, Borg A, Grenman S, et al. Amplification and deletion of topoisomerase IIalpha associate with ErbB-2 amplification and affect sensitivity to topoisomerase II inhibitor doxorubicin in breast cancer. Am J Pathol. 2000;156:839-47.

78. Rouzier R, Rajan R, Wagner P, Hess KR, Gold DL, Stec J, et al. Microtubule-associated protein tau: a marker of paclitaxel sensitivity in breast cancer. Proc Natl Acad Sci USA. 2005;102:831520.

79. Pusztai L. Markers predicting clinical benefit in breast cancer from microtubule-targeting agents. Ann Oncol. 2007;18 Suppl 12: xii15-20.

80. Andre F, Hatzis C, Anderson K, Sotiriou C, Mazouni C, Mejia $\mathrm{J}$, et al. Microtubule-associated protein-tau is a bifunctional predictor of endocrine sensitivity and chemotherapy resistance in estrogen receptor-positive breast cancer. Clin Cancer Res. 2007;13:2061-7. 